\title{
Theoretical Analysis of Safety Thickness of the Water-Resistant Rock Mass of Karst Tunnel Face Taking Into Account Seepage Effect
}

Jiaqi GUO

Henan polytechnic university https://orcid.org/0000-0002-0093-7923

Wenlong Wu ( $\sim$ hpuwwl@qq.com )

Henan Polytechnic University

Xiliang Liu

Henan Polytechnic University

Xin Huang

Henan Polytechnic University

Zhengguo Zhu

Shijiazhuang Tiedao University

\section{Research Article}

Keywords: Karst tunnel, Water-resistant rock mass, Safety thickness, Upper limit analysis, Seepage effect

Posted Date: April 19th, 2021

DOl: https://doi.org/10.21203/rs.3.rs-384740/v1

License: (9) This work is licensed under a Creative Commons Attribution 4.0 International License. Read Full License

Version of Record: A version of this preprint was published at Geotechnical and Geological Engineering on July 8th, 2021. See the published version at https://doi.org/10.1007/s10706-021-01916-7. 
1 Theoretical analysis of safety thickness of the water2 resistant rock mass of karst tunnel face taking into

3 account seepage effect

4

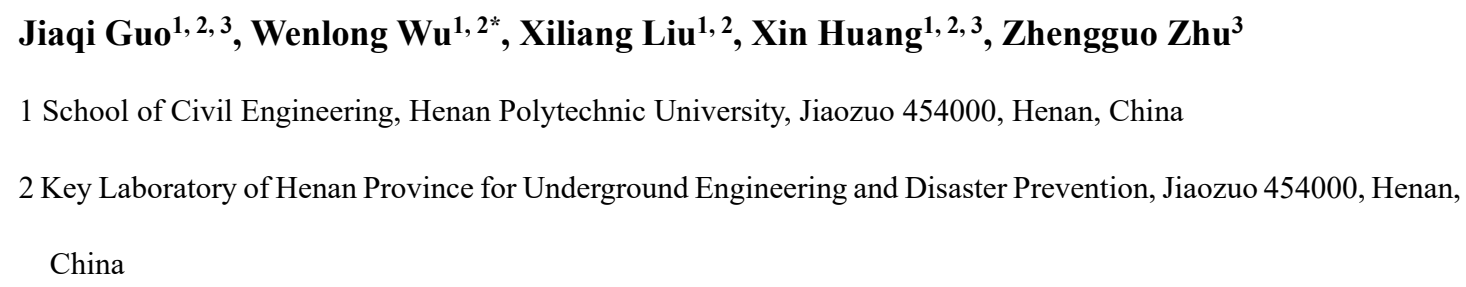

Abstract: This paper took into account the adverse influence of the karst water seepage effect on the water-resistant rock mass. Based on the upper-bound theorem of limit analysis and the HoekBrown failure criterion, through a series of formula derivation, the expression of critical safety thickness of water-resistant rock mass of karst tunnel face was finally obtained. The paper carried out a feasibility analysis, an analysis of influencing factors and a comparative analysis with previous related research achievements of this method. The results showed that: (1) With the decrease of surrounding rock grade, the safety thickness of water-resistant rock mass gradually increased, and the safety thickness of surrounding rock at all grades remained within a reasonable range. (2) The safety thickness decreased as the compressive strength, the tensile strength and parameter $A$ increased, and it increased as the karst water pressure, the tunnel excavation height, and parameter $B$ increased. (3) The change trend of the safety thickness with the influencing factors was completely consistent under the two conditions of considering and without the seepage effect, and the safety thickness with considering the seepage force was greater than that without considering the seepage force. Taking the Yunwushan tunnel of Yiwan railway as an example, the critical safety thickness of the water-resistant rock mass was calculated and the calculated value was in good coincidence with the safety thickness adopted in the actual project. The research results are of great significance to prevent the occurrence of high pressure filling karst geological disasters such as water inrush in tunnels.

Keywords: Karst tunnel; Water-resistant rock mass; Safety thickness; Upper limit analysis; Seepage 
effect

\section{Introduction}

China has a vast territory, $70 \%$ of which are mountainous areas. The geographical and geological conditions are very complex. It is the country with the widest distribution of karst in the world. With the rapid development of highway, railway and other transportation infrastructure construction in southwest China, karst tunnel water inrush disasters are increasingly frequent. Water pressure filling cavity and other karst structural forms are often developed in front of karst tunnel face. In tunnel engineering, when the excavation reaches a certain thickness behind the highpressure water-rich karst cavity of the tunnel face, if the construction is not stopped or measures such as pre-reinforcement are not taken, the combined effects of the hydraulic pressure and the excavation disturbance likely will cause the water-resistant rock mass of the tunnel face to collapse, resulting in a water-inrush disaster (Guo et al. 2017). Therefore, the safety thickness of the waterresistant rock mass of face is an important technical parameter to ensure the safe construction of karst tunnel.

Scholars at home and abroad have calculated the safety thickness of water-resistant rock mass with various methods and given the corresponding calculation formulas. Li et al. (2015) deduced the calculation formula of minimum safety thickness of cracked rock mass under blasting excavation disturbance and water pressure, which was verified by engineering examples. Zhang et al. (2018) proposed the calculation method of minimum safety thickness of stable rock mass of tunnel face by combining theoretical calculation, numerical simulation and engineering practice. Based on two band theory and critical water pressure, Guo et al. (2019) established the safety thickness of waterresistant strata with multi fractures ahead of karst tunnel. Meng et al. (2020) established models of water inrush in fault fracture zone and obtained the calculation formula of minimum safety thickness. These achievements are mostly based on specific engineering cases, and each research direction has its own emphasis, different mechanical models, influencing factors, and judgment standards. In recent years, the limit analysis principle has been widely used in solving the problem of the safety thickness of water-resistant rock mass of tunnel face. By means of the upper bound theorem and variation principle, Yang et al. (2016) deduced the calculation processes of rock plug thickness and obtained the expression of minimum safe thickness. On the basis of a plane failure pattern of rock plug, Yang et al. (2017) employed the limit analysis principle and derived the expressions of 
detaching curve and rock plug thickness. None of the above studies considered the adverse influence of karst water seepage effect on water-resistant rock mass.

On the basis of the upper-bound theorem of limit analysis and the Hoek-Brown failure criterion, we derived and obtained the expression of the critical safety thickness of the water-resistant rock mass of karst tunnel face considering the adverse influence of karst water seepage effect on the water-resistant rock mass. The feasibility of the application of the method was analysed, the analysis of influencing factors affecting the safety thickness of water-resistant rock mass was executed, and the comparative analysis was carried out with the previous related research achievements. We took the Yunwushan tunnel of Yiwan railway as an example for an engineering application to verify the rationality and practicability of the method proposed in this paper. The research results are of great significance to prevent the occurrence of high pressure filling karst geological disasters such as water inrush in tunnels.

\section{Basic principles}

\subsection{Upper limit theorem of the limit analysis considering the seepage effect}

The upper limit theorem can be stated as follows (Chen 2013): If the assumed maneuvers allowable velocity field satisfies the displacement boundary conditions, the load determined by equating the internal energy dissipation rate to the external work rate must be greater than or equal to the actual load in the limit state. When considering the adverse influence of the seepage effect on the water-resistant rock mass of a tunnel face, the seepage force is regarded as the external force acting on the rock and the soil skeleton. Therefore, the mathematical expression of the upper limit theorem is

$$
\int_{\Omega} D\left(\dot{\varepsilon}_{i j}\right) \mathrm{d} \Omega \geqslant \int_{S} T_{i} v_{i} \mathrm{~d} S+\int_{\Omega} F_{i} v_{i} \mathrm{~d} \Omega+\int_{\Omega} f_{\mathrm{s}} v_{i} \mathrm{~d} \Omega
$$

where $D\left(\dot{\varepsilon}_{i j}\right)$ is the internal energy dissipation rate of the plastic strain rate vector; $T_{i}$ and $F_{i}$ are the area force and volume force, respectively; $v_{i}$ is the velocity vector in the maneuvering velocity field; $S$ and $\Omega$ are the surface area and volume of the research object, respectively; and $f_{\mathrm{s}}$ is the seepage force.

\subsection{Hoek-Brown nonlinear failure criterion}

Since Hoek and Brown proposed the Hoek-Brown nonlinear failure criterion in 1980 (Hoek and Brown 1980a, b), their criterion has been widely used by scholars in the industry, and the HoekBrown failure criterion has been demonstrated to be an appropriate yield function for evaluating the 
strength and stability of rock masses in karst regions (Huang et al. 2017). The two classical expressions of the Hoek-Brown failure criterion (H-B criterion) (Hoek and Brown 1997) are expressed (1) using the large principal stress and the small principal stress, and (2) using the normal stress and the shear stress. The normal stress and shear stress parameters of the unit body should be considered when calculating the internal energy dissipation. Thus, it is convenient to use the second form of the Hoek-Brown failure criterion. Its mathematical expression is as follows:

$$
\tau_{\mathrm{n}}=A \sigma_{\mathrm{ci}}\left(\frac{\sigma_{\mathrm{n}}+\sigma_{\mathrm{tm}}}{\sigma_{\mathrm{ci}}}\right)^{B}
$$

where $\tau_{\mathrm{n}}$ and $\sigma_{\mathrm{n}}$ are the normal stress and shear stress, respectively; and the parameters $A$ and $B$ are dimensionless material constants that can be obtained through triaxial compression tests. When $B=$ 1, the $\mathrm{H}-\mathrm{B}$ criterion becomes the M-C linear yield criterion. $\sigma_{\mathrm{ci}}$ is the uniaxial compressive strength of the intact rock, which can be obtained through experiments. $\sigma_{\mathrm{tm}}$ is the tensile strength of the rock mass, and its value can be calculated by the following formula:

$$
\sigma_{\mathrm{tm}}=\frac{\sigma_{\mathrm{ci}}}{2}\left\{m_{\mathrm{i}} \exp \left(\frac{G S I-100}{28-14 D_{\mathrm{i}}}\right)-\sqrt{\left[m_{\mathrm{i}} \exp \left(\frac{G S I-100}{28-14 D_{\mathrm{i}}}\right)\right]^{2}+4 \exp \left(\frac{G S I-100}{9-3 D_{\mathrm{i}}}\right)}\right\}^{B}
$$

where $m_{\mathrm{i}}$ is a parameter reflecting the degree of hardness and softness of rock; GSI is a geological strength index, $D_{\mathrm{i}}$ is the disturbance parameter of jointed rock mass.

\section{Critical safety thickness of the water-resistant rock mass of karst tunnel face}

\subsection{Failure mode of the water-resistant rock mass}

In this paper, we established the failure mode of the water-resistant rock mass (Fig. 1) according to the model of Fraldi and Guarracino (2009).

\footnotetext{
Fig. 1 Failure mode of the water-resistant rock mass
}

In Fig. 1, $D$ is the height of the excavated tunnel section; $w$ is the separation layer thickness when the water-resistant rock mass is broken; $S$ is the safety thickness of the water-resistant rock mass, which is an unknown quantity to be determined according to the limit analysis theory; $f_{\mathrm{s}}$ is the seepage force on the rock mass; $p$ is the karst cavity pressure, which is equal to the hydrostatic pressure $p_{\mathrm{w}}$; and $L$ is the effective range of the karst cavity pressure. In addition, it is assumed that the karst cavity pressure is uniformly distributed perpendicular to the surface of the water-resistant rock mass, and the stress surface is simplified into a plane, that is, the dotted line in Fig. 1(a) 
coincides with the $x$-axis.

As shown in Fig. 1, the water-resistant rock mass of the tunnel face exhibits an overall squeezing failure mode at a speed $v$ under various external forces, and the failure surface is composed of two separation curves $f(x)$ and $f(-x)$, which are symmetric about the $y$-axis. To simplify the calculation, we selected the water-resistant rock mass in the positive direction of the $x$-axis as the research object. We established a local coordinate system $s-n$ (Fig. 1(b)) on the micro-unit of the separation layer with the tangent and the outer normal as the positive directions. Thus, the algebraic relationship between the angle $\theta$ and $f^{\prime}(x)$ is as follows:

$$
\left\{\begin{array}{l}
\sin \theta=f^{\prime}(x)\left[1+f^{\prime}(x)^{2}\right]^{-\frac{1}{2}} \\
\cos \theta=\left[1+f^{\prime}(x)^{2}\right]^{-\frac{1}{2}}
\end{array}\right.
$$

\subsection{Calculation of the critical safety thickness of the water-resistant rock mass}

\subsubsection{Objective function}

As shown in Fig. 1(b), the micro-unit moves from the dotted line (state 1) to the solid line (state 2) with speed $v$, and the separation layer exhibits shear deformation along the tangential direction and tensile deformation along the normal direction. Therefore, the energy dissipation rate of the micro-unit can be expressed as follows:

$$
D\left(\dot{\varepsilon}_{i j}\right)=l\left(\tau_{\mathrm{n}} \dot{\gamma}+\sigma_{\mathrm{n}} \dot{\varepsilon}\right)
$$

where $l$ is the area of the corresponding separation layer, which has a value of $w ; \dot{\varepsilon}$ and $\dot{\gamma}$ are the positive and tangential strain rates, respectively. According to the definition of strain rate and the trigonometric function, the mathematical expressions for $\dot{\varepsilon}$ and $\dot{\gamma}$ are as follows:

$$
\left\{\begin{array}{l}
\dot{\varepsilon}=-\frac{v_{\mathrm{n}}}{l}=-\frac{v}{w}\left[1+f^{\prime}(x)^{2}\right]^{-\frac{1}{2}} \\
\dot{\gamma}=\frac{v_{\mathrm{s}}}{l}=\frac{v}{w} f^{\prime}(x)\left[1+f^{\prime}(x)^{2}\right]^{-\frac{1}{2}}
\end{array}\right.
$$

where $v_{\mathrm{n}}$ and $v_{\mathrm{s}}$ are the normal velocity and tangential velocity of the micro-unit respectively. In addition, soil mechanics stipulates that when shear failure occurs in geotechnical materials, the compressive stress is positive and the tensile stress is negative. When the tensile deformation of the separation layer occurs along the normal direction, the value $\dot{\varepsilon}$ is considered to be negative.

On the basis of the aforementioned basic theorem, in this paper, we used the H-B failure criterion and considered the influence of the correlation flow rule. This rule not only meets the basic assumption of the limit analysis but also ensures that the yield surface coincides with the plastic potential surface. Thus, the plastic potential function $g\left(\sigma_{\mathrm{n}}, \tau_{\mathrm{n}}\right)$ can be expressed by the yield function 
$f\left(\sigma_{\mathrm{n}}, \tau_{\mathrm{n}}\right)$ when the material yields, and its mathematical expression is

$$
g\left(\sigma_{\mathrm{n}}, \tau_{\mathrm{n}}\right)=f\left(\sigma_{\mathrm{n}}, \tau_{\mathrm{n}}\right)=\tau_{\mathrm{n}}-A \sigma_{\mathrm{ci}}\left(\frac{\sigma_{\mathrm{n}}+\sigma_{\mathrm{tm}}}{\sigma_{\mathrm{ci}}}\right)^{B}
$$

According to the orthogonal flow law, the normal strain rate $\dot{\varepsilon}$ and the tangential strain rate $\dot{\gamma}$ can also be expressed as

$$
\left\{\begin{array}{l}
\dot{\varepsilon}=\lambda \frac{\partial g}{\partial \sigma_{\mathrm{n}}}=-\lambda A B\left(\frac{\sigma_{\mathrm{n}}+\sigma_{\mathrm{tm}}}{\sigma_{\mathrm{ci}}}\right)^{B-1} \\
\dot{\gamma}=\lambda \frac{\partial g}{\partial \tau_{\mathrm{n}}}=\lambda
\end{array}\right.
$$

where $\lambda$ is the plastic ratio coefficient greater than 0 . The expression for the normal stress $\sigma_{\mathrm{n}}$ can be obtained by eliminating $\lambda$ and $w$ in simultaneous Eqs. (6) and (8).

$$
\sigma_{\mathrm{n}}=\sigma_{\mathrm{ci}}\left[A B f^{\prime}(x)\right]^{\frac{1}{1-B}}-\sigma_{\mathrm{tm}}
$$

By substituting Eqs. (3), (6), and (9) into Eq. (5), the internal energy dissipation rate of the micro-unit on the separation curve $f(x)$ can be obtained, as follows:

$$
D\left(\dot{\varepsilon}_{i j}\right)=l\left(\tau_{\mathrm{n}} \dot{\gamma}+\sigma_{\mathrm{n}} \dot{\varepsilon}\right)=v\left[1+f^{\prime}(x)^{2}\right]^{-\frac{1}{2}}\left\{\sigma_{\mathrm{tm}}-\sigma_{\mathrm{ci}}\left(1-B^{-1}\right)\left[A B f^{\prime}(x)\right]^{\frac{1}{1-B}}\right\}
$$

According to the lateral area integration formula, Eq. (10) was integrated along the total separation line, and the internal energy dissipation rate of the water-resistant rock mass was obtained:

$$
\dot{W}_{D}=\int_{\Omega} D\left(\dot{\varepsilon}_{i j}\right) \mathrm{d} \Omega=\int_{L / 2}^{D / 2}\left\{\sigma_{\mathrm{tm}}-\sigma_{\mathrm{ci}}\left(1-B^{-1}\right)\left[A B f^{\prime}(x)\right]^{\frac{1}{1-B}}\right\} v \mathrm{~d} x
$$

Then, we calculated the work power of the external force. Under this failure mode, the external load can be divided into the karst cavity pressure, the seepage force, and the rock mass gravity. The karst cavity pressure is the surface force, and the work power can be expressed as

$$
\dot{W}_{p_{\mathrm{w}}}=\int_{S} T_{i} v_{i} \mathrm{~d} S=\frac{1}{2} p v L=\frac{1}{2} p_{\mathrm{w}} v L
$$

The gravity of the rock mass is the volume force, and it is always perpendicular to the movement direction of the rock mass. Therefore, throughout the failure process, the work done by gravity is equal to 0 , that is

$$
\dot{W}_{\gamma}=\int_{\Omega} F_{i} v_{i} \mathrm{~d} \Omega=0
$$

The seepage of water occurs in the pores of the water-resistant rock mass. Under the action of the water head difference, the groundwater flows through the pores of the water-resistant rock mass. Generally, the horizontal component of the tunnel face seepage force is far greater than the vertical component, so we considered only the influence of the horizontal component of the seepage force 
on the stability of the tunnel face (Lee and Nam 2001). The seepage force of the rock and soil mass per unit volume along the streamline direction is

$$
f_{\mathrm{s}}=\gamma_{\mathrm{w}} i=\gamma_{\mathrm{w}} \frac{\Delta h}{S}
$$

where $\gamma_{\mathrm{w}}$ is the volumetric weight of the groundwater; $i$ is the hydraulic gradient; $\Delta h$ is the water head difference; and $S$ is the seepage length, that is, the safety thickness of the water-resistant rock mass. For a rock and soil mass with volume $V$, the seepage force along the streamline direction is

$$
F_{\mathrm{s}}=\gamma_{\mathrm{w}} i V=f_{\mathrm{s}} V
$$

Therefore, the power of the work done by the internal seepage force of water-resistant rock mass is

$$
\dot{W}_{f_{\mathrm{s}}}=\int_{\Omega} f_{\mathrm{s}} v_{i} \mathrm{~d} \Omega=\int_{L / 2}^{H / 2} \gamma_{\mathrm{w}} i f(x) v \mathrm{~d} x
$$

By substituting Eqs. (11), (12), (13), and (16) into Eq. (1), the objective function, including the separation curve $f(x)$, is obtained

$$
\begin{aligned}
& \xi\left[f(x), x, f^{\prime}(x)\right]=\int_{L / 2}^{D / 2}\left\{\sigma_{\mathrm{tm}}-\sigma_{\mathrm{ci}}\left(1-B^{-1}\right)\left[A B f^{\prime}(x)\right]^{\frac{1}{1-B}}\right\} v \mathrm{~d} x-\frac{1}{2} p_{\mathrm{w}} v L \\
& -\int_{L / 2}^{D / 2} \gamma_{\mathrm{w}} i f(x) v \mathrm{~d} x=\int_{L / 2}^{D / 2} \phi\left[f(x), x, f^{\prime}(x)\right] v \mathrm{~d} x+\frac{1}{2} \sigma_{\mathrm{tm}} v(D-L)-\frac{1}{2} p_{\mathrm{w}} v L
\end{aligned}
$$

Where

$$
\phi\left[f(x), x, f^{\prime}(x)\right]=-\sigma_{\mathrm{ci}}\left(1-B^{-1}\right)\left[A B f^{\prime}(x)\right]^{\frac{1}{1-B}}-\gamma_{\mathrm{w}} i f(x)
$$

\subsubsection{Separation curve equation}

As evident from Eqs. (16) and (17), the extreme value of the objective function $\xi$ is completely determined by the function $\varphi$. Therefore, solving for the extreme value of $\xi$ also solves for the extreme value of $\phi$. According to the variational principle, it can be transformed into a Euler equation, so that the extreme value problem can be transformed to solve the definite solution of the Euler equation under the boundary conditions. The Euler equation of $\phi$ is

$$
\frac{\partial \phi}{\partial f(x)}-\frac{\mathrm{d}}{\mathrm{d} x}\left[\frac{\partial \phi}{\partial f^{\prime}(x)}\right]=0
$$

According to Eq. (18), the following equation can be obtained by combining Eq. (18) with Eq. (19):

$$
\frac{\partial \phi}{\partial f(x)}=-\gamma_{\mathrm{w}} i
$$




$$
\begin{gathered}
\frac{\partial \phi}{\partial f^{\prime}(x)}=\frac{\sigma_{\mathrm{ci}}(A B)^{\frac{1}{1-B}}}{B} f^{\prime}(x)^{\frac{B}{1-B}} \\
\frac{\mathrm{d}}{\mathrm{d} x}\left[\frac{\partial \phi}{\partial f^{\prime}(x)}\right]=\frac{\sigma_{\mathrm{ci}}(A B)^{\frac{1}{1-B}}}{1-B} f^{\prime}(x)^{\frac{2 B-1}{1-B}} f^{\prime \prime}(x)
\end{gathered}
$$

Eqs. (20) and (22) are substituted into Eq. (19), and after sorting and simplifying, the following equation is obtained:

$$
f^{\prime}(x)^{\frac{2 B-1}{1-B}} f^{\prime \prime}(x)=\frac{\gamma_{\mathrm{w}} i(B-1)}{\sigma_{\mathrm{ci}}(A B)^{\frac{1}{1-B}}}
$$

By solving this second-order differential equation, the expression for the separation curve $f(x)$ can be obtained:

$$
f(x)=\frac{\sigma_{\mathrm{ci}}(A B)^{\frac{1}{1-B}}}{-\gamma_{\mathrm{w}} i}\left[\frac{-\gamma_{\mathrm{w}} i B}{\sigma_{\mathrm{ci}}(A B)^{\frac{1}{1-B}}} x+C_{1}\right]^{\frac{1}{B}}+C_{2}
$$

where $C_{1}$ and $C_{2}$ are undetermined constants. Then the mathematical expression of $f^{\prime}(x)$ can be obtained :

$$
f^{\prime}(x)=\left[\frac{-\gamma_{\mathrm{w}} i B}{\sigma_{\mathrm{ci}}(A B)^{\frac{1}{1-B}}} x+C_{1}\right]^{\frac{1-B}{B}}
$$

It can be seen from Fig. 1 that the separation curve $f(x)$ is symmetric about the $y$-axis and continuously differentiable in its domain, which is an even function. This indicates that when $x=0$, $f^{\prime}(x)=0$, namely:

$$
f^{\prime}(0)=\left(C_{1}\right)^{\frac{1-B}{B}}=0
$$

It can be seen that the value of $C_{1}$ is 0 . Therefore, the expression of $f(x)$ can be simplified to:

$$
f(x)=\frac{\left(-\gamma_{w} i\right)^{\frac{1-B}{B}}}{A^{\frac{1}{B}} \sigma_{\mathrm{ci}}^{\frac{1-B}{B}}} x^{\frac{1}{B}}+C_{2}
$$

Taking the separation curve as a generatrix rotating around the $y$-axis, the expression of discontinuity caused by the failure of water-resistant rock mass can be obtained:

$$
f(x, z)=\frac{\left(-\gamma_{w} i\right)^{\frac{1-B}{B}}}{A^{\frac{1}{B}} \sigma_{\mathrm{ci}}^{\frac{1-B}{B}}}\left(x^{2}+z^{2}\right)^{\frac{1}{2 B}}+C_{2}
$$




\subsubsection{Expression of critical safety thickness of water-resistant rock mass}

According to the geometric relationship of the failure mode in Fig. 1(a) and the expression of the separation curve $f(x)$, the following equations can be obtained:

$$
\left\{\begin{array}{l}
f\left(\frac{L}{2}\right)=\frac{\left(-\gamma_{w} i\right)^{\frac{1-B}{B}}}{A^{\frac{1}{B}} \sigma_{\mathrm{ci}}^{\frac{1-B}{B}}}\left(\frac{L}{2}\right)^{\frac{1}{B}}+C_{2}=0 \\
f\left(\frac{D}{2}\right)=\frac{\left(-\gamma_{w} i\right)^{\frac{1-B}{B}}}{A^{\frac{1}{B}} \sigma_{\mathrm{ci}}^{\frac{1-B}{B}}}\left(\frac{D}{2}\right)^{\frac{1}{B}}+C_{2}=S
\end{array}\right.
$$

Substitute hydraulic gradients $i=\Delta h / S$ and $\Delta h=p_{\mathrm{w}} / \gamma_{\mathrm{w}}$ into Eq. (29) to simplify, The expression of critical safety thickness of water-resistant rock mass based on the Hoek-Brown failure criterion can be obtained:

$$
S=\frac{p_{\mathrm{w}}^{1-B}}{A \sigma_{\mathrm{ci}}^{1-B}}\left[\left(\frac{D}{2}\right)^{\frac{1}{B}}-\left(\frac{L}{2}\right)^{\frac{1}{B}}\right]^{B}
$$

where the parameter $L$ is an unknown number, so the critical safe thickness of water-resistant rock mass can be calculated according to the mechanical boundary conditions.

According to the mechanical boundary conditions, the micro-unit located at the interface between the separation curve and the water-filled karst cave is selected for mechanical analysis, and the mechanical equilibrium equation is established in the vertical direction. After derivation and simplification, the mathematical expression of the shear stress $\tau_{y x}$ is:

$$
\tau_{y x}=\frac{\sigma_{n} \sin 2 \theta}{2}-\tau \cos 2 \theta
$$

Considering the assumption that the karst cavity pressure is uniform and vertically distributed, there is no shear stress on the surface of the karst cavity, so $\tau_{y x}$ is 0 at $(x=L / 2, y=0)$. Substituting Eqs. (3), (4), (9) into Eq. (31) to simplify:

$$
\sigma_{\mathrm{ci}}(A B)^{\frac{1}{1-B}} f^{\prime}(x)^{\frac{2-B}{1-B}}-\sigma_{\mathrm{tm}} f^{\prime}(x)=\sigma_{\mathrm{ci}} A^{\frac{1}{1-B}} B^{\frac{B}{1-B}}\left[f^{\prime}(x)^{\frac{B}{1-B}}-f^{\prime}(x)^{\frac{1}{1-B}}\right]
$$

Substituting the expression of $f^{\prime}(x)$ and $x=L / 2$ into Eq. (32), the result is as follows:

$$
\left(\frac{p_{\mathrm{w}} L}{2 S \sigma_{\mathrm{ci}}}\right)^{\frac{2-2 B}{B}} \frac{1}{A^{\frac{2}{B}} B}+\left(\frac{p_{\mathrm{w}} L}{2 S \sigma_{\mathrm{ci}}}\right)^{\frac{1-B}{B}} \frac{1}{A^{\frac{1}{B}} B}-\left(\frac{p_{\mathrm{w}} L}{2 S}\right)^{\frac{2-2 B}{B}} \frac{\sigma_{\mathrm{tm}}}{\sigma_{\mathrm{ci}}^{\frac{2-B}{B}} A^{\frac{2-B}{B-B^{2}}} B^{\frac{2-B}{1-B}}}=1
$$

When the basic parameters are determined, the critical safety thickness of the water-resistant 
rock mass conforming to the Hoek-Brown failure criterion can be obtained using simultaneous Eqs. (30) and (33).

\section{Results analysis}

\subsection{Feasibility analysis}

In order to verify the feasibility of the above method, we calculated the critical safety thickness of the water-resistant rock mass under I-V grade surrounding rock. The parameter $c$ and $\varphi$ were selected according to Standard for engineering classification of rock mass (GB/T 50218-2014). The tunnel section height was $10 \mathrm{~m}$, the karst water pressure was $1.0 \mathrm{MPa}$, the parameters $A$ and $B$ were 0.8 and 0.5 respectively, and tensile strength was $1 / 100$ of compressive strength for calculation. The calculation results are shown in Table $\mathbf{1}$.

Table 1 Critical safety thickness of the water-resistant rock mass with different surrounding rock grades

It could be seen from the calculation results in Table $\mathbf{1}$ that with the decrease of surrounding rock grades, the critical safety thickness of the water-resistant rock mass gradually increased, and the safety thickness of surrounding rock at all grades were all within a reasonable range (Huang et al. 2019), which verified the feasibility of the method in this paper to a certain extent. The specific engineering case will be given in the second half of the paper.

\subsection{Analysis of influencing factors}

On the basis of the previous theoretical equation, the main factors affecting the safety thickness of the water-resistant rock mass of tunnel face are the compressive strength $\sigma_{\mathrm{ci}}$ and tensile strength $\sigma_{\mathrm{tm}}$ of the water-resistant rock mass, the karst water pressure $p_{\mathrm{w}}$, the tunnel section height $D$, and parameters $A$ and $B$. The factors have different degrees of influence on the failure range of the waterresistant rock mass (Yang and Long 2015) and we analyzed the influences of the changes in these factors on the safety thickness of the water-resistant rock mass.

In order to study the influence of single factor change on the safety thickness of water-resistant rock mass, the safety thickness of water-resistant rock mass is obtained according to Eqs (30) and (33) when other factors are determined. In order to more clearly determine how the safety thickness of the water-resistant rock mass changes as the change of each factor, we combined the typical data in calculation results with the separation curve and the separation surface equation, and drew the failure shape and damage range of the water-resistant rock mass as diagrams (Fig. 2). 
Fig. 2 Influence of each factor on the failure shape and damage range of the water-resistant rock mass

As shown in Fig. 2, the safety thickness decreased as the compressive strength, the tensile strength of the water-resistant rock mass, and parameter $A$ increased, and it increased as the karst water pressure, the tunnel excavation height, and parameter $B$ increased. Comparing the influence law of each factor change on the safety thickness of the water-resistant rock mass, it was found that the change of parameter $A$ and $B$ had the most significant influence on the safety thickness. Therefore, in practical engineering application, according to the I-V grade of surrounding rock and the good to bad lithological conditions, it was suggested that the value of $A$ should be $0.9-0.4$ and the value of $B$ should be $0.5-0.8$, so as to ensure that the thickness of the water-resistant rock mass could have a certain safety reserve.

\subsection{Comparative analysis with previous research achievements}

In order to verify the effectiveness and consistency of the method in this paper, it is necessary to make a comparative analysis with previous related research achievements. For example, Yang et al. (2017) proposed a calculation method for the thickness of the karst tunnel rock wall based on the Hoek-Brown criterion without considering the seepage effect. In this paper, "whether or not to consider the influence of seepage effect on the safety thickness of the water-resistant rock mass in water-rich area" was taken as the breakthrough point to compare with the research achievements (Yang et al. 2017) to verify the correctness of this method. In order to ensure the reliability of the analysis results, the selection of the calculation parameters and the value of the data should be consistent with the comparison literature as much as possible to meet the requirements of the homologous feature parameters. The influence law of each factor change on the critical safety thickness of the water-resistant rock mass with or without seepage effect is plotted as a graph for comparison, as shown in Fig. 3.

Fig. 3 Variation law of safety thickness under the influence of different factors

Different safety thickness calculation formulas have different value categories for the parameters $A$ and $B$, so the values of $A$ and $B$ in figures (e) and (f) are not exactly same. It could be clearly seen from Fig. 3 that the safety thickness of the water-resistant rock mass had the same trend with the change of factors in the case of considering and not considering the seepage effect, that is, the safety thickness decreased with the increase of compressive strength, tensile strength and 
parameter $A$, and increased with the increase of karst water pressure, excavation height and parameter $B$. It could also be concluded from Fig. 3 that in the case of considering the seepage effect, the safety thickness of the water-resistant rock mass was greater than that without considering the seepage effcet. Combining with the specific data, under the influence of the excavation section height, the maximum difference of the critical safety thickness was $4.16 \mathrm{~m}$, and under the influence of parameter $A$, the minimum difference of the critical safety thickness was $0.98 \mathrm{~m}$. That is, in the process of tunnel excavation, when the seepage effect of groundwater is considered, the reserved safety thickness of the water-resistant rock mass is at least $1 \mathrm{~m}$ or even $4 \mathrm{~m}$ more than that without considering seepage effect. It also showed that the seepage effect had a significant influence on the stability of surrounding rock of underground tunnel. Therefore, the seepage effect of groundwater must be fully considered in tunnel construction in areas rich in groundwater.

\section{Engineering application}

The entrance of Yunwushan tunnel of Yiwan railway line is located in Ginguba Town of Enshi city, and the exit is located in Zhoujiawan of Tunbao Township of Enshi City. The total length of tunnel line I is $6640 \mathrm{~m}$ with the mileage of DK242+084 DK248+724 and the total length of tunnel line II is $6682 \mathrm{~m}$ with the mileage of IIDK242+084 IIDK248+766. The line II tunnel is located on the left side of the line I tunnel with a distance of $30 \mathrm{~m}$ between the two lines. On October 12, 2008, IIDK242 +526 karst cavity was encountered in front of the working face of line II at the entrance of Yunwushan Tunnel, and the karst cavity was filled with mud and sand. During the detection period, the protruding mud sand was about $250 \mathrm{~m}^{3}$, and the water inflow was about $90 \mathrm{~m}^{3} / \mathrm{h}$. The location of the karst cavity was shown in Fig. 4 (Guo 2011). According to Yunwushan Tunnel Engineering Geology Report (Qiao 2009), Yunwushan Tunnel passes through strata dominated by limestone and argillaceous dolomite, the basic grade of surrounding rock is grade III, and the average value of saturated uniaxial compressive strength is $67.34 \mathrm{MPa}$. There are fault fracture zones and influence zones in the range of DK245+504.8 DK245+633.8 with rock fragmentation lithification and breccification, karst water development, and cavity water pressure of $0.8 \mathrm{MPa}$. The depth of the tunnel is more than $500 \mathrm{~m}$, the height of the section is $9.8 \mathrm{~m}$, and the span is $7 \mathrm{~m}$.

Fig. 4. Engineering geological profile of the Yunwushan tunnel and the karst cave 526 location

The karst cave of the face was divided into four areas: the thickness of water-resistant rock mass in zone I was less than $2.5 \mathrm{~m}$, the thickness of water-resistant rock mass in zone II was $2.5-$ $4.5 \mathrm{~m}$, the thickness of water-resistant rock mass in zone III was 4.5-9 m, and the thickness of water- 
resistant rock mass in zone IV was greater than 9 m, as shown in Fig. 5 (Guo 2011). Therefore, in order to ensure the construction safety and smooth, it is necessary to open the karst cavity zone I and II.

Fig. 5 Boundary locking value of karst cavity 526 in Yunwushan Tunnel

The parameters of Hoek-Brown failure criterion (Hoek and Brown 1997): $m_{\mathrm{i}}=9, G S I=60, D_{\mathrm{i}}=$ $0.8, A=0.5, B=0.8$. By substituting the above parameters into the method discussed in this paper, the critical safety thickness of water-resistant rock mass was calculated to be $3.71 \mathrm{~m}$, which was within the range of the adopted safety thickness $(2.5-4.5 \mathrm{~m})$ in the actual project of karst cavity 526 and was equivalent to the average value $(3.5 \mathrm{~m})$, so the result was relatively safe. Therefore, this method is reasonable and feasible to calculate the safety thickness of water-resistant rock mass, which can be used to guide the construction of tunnels in karst areas and provide a decision-making reference for preventing water and mud inrush in karst tunnels.

\section{Conclusion}

(1) The current methods for calculating the safety thickness of the water-resistant rock mass of karst tunnel face in the water-rich area do not consider the karst water seepage effect. This paper took into account the adverse influence of the karst water seepage effect on the water-resistant rock mass. Based on the upper-bound theorem of limit analysis and the Hoek-Brown failure criterion, through a series of formula derivation, the undetermined constant was solved by using the property of even function, and the expression of critical safety thickness of water-resistant rock mass of face was finally obtained.

(2) We conducted a feasibility analysis and an analysis of influencing factors. The results showed that with the decrease of surrounding rock grade, the safety thickness of water-resistant rock mass gradually increased, and the safety thickness of surrounding rock at all grades remained within a reasonable range; the safety thickness of the water-resistant rock mass of face decreased as the compressive strength, tensile strength, and parameter $A$ increased and it increased as the karst water pressure, tunnel excavation height, and parameter $B$ increased.

(3) We carried out a comparative analysis with the previous relevant research achievements, which showed the change trend of the safety thickness with the parameters was completely consistent under the two conditions of considering the seepage effect and without considering the seepage effect, and the safety thickness with considering the seepage effect was greater than that without 
considering the seepage effect. Taking the Yunwushan tunnel of Yiwan railway as an example, the critical safety thickness of the water-resistant rock mass was calculate and the calculated value was in good coincidence with the safety thickness adopted in the actual project.

\section{Acknowledgments}

This study was financially supported by the National Natural Science Foundation of China (Grant No.: 51778215, U1810203), the National Key Basic Research and Development Plan (973 Plan) Project (Grant No.: 2013CB036003), the China Postdoctoral Science Foundation Fund (Grant No.: 2018M631114), and the Doctoral Fund of Henan Polytechnic University (Grant No.: B202041).

\section{Disclosure statement}

The authors declare that they have no conflicts of interest.

\section{References}

Chen WF (2013) Limit analysis and soil plasticity. Elsevier, Netherland

Fraldi M, Guarracino F (2009) Limit analysis of collapse mechanisms in cavities and tunnels according to the Hoek-Brown failure criterion. Int J Rock Mech Min 46(4): 665-673

Guo JQ (2011) Study on against-inrush thickness and waterburst mechanism of karst tunnel. Ph.D thesis, Beijing Jiaotong University, Beijing

Guo JQ, Li HF, Chen F, He ZY (2017) Theoretical analysis on water-resisting thickness of karst tunnel face. Chin J Underground Space Eng 13(5): 1373-1380

Guo JQ, Qian Y, Chen JX, Chen F (2019) The minimum safe thickness and catastrophe process for water inrush of a karst tunnel face with multi fractures. Processes 7: 686.

Hoek E, Brown ET (1980a) Empirical strength criterion for rock masses. J Geotech Geoenviron 106(GT9): 1013-1035

Hoek E, Brown ET (1980b) Underground excavations in rock. Institute of Miningand Metallurgy, London

Hoek E, Brown ET (1997) Practical estimates of rock mass strength. Int J Rock Mech Min 34(8): $1165-1186$

Huang F, Zhao LH, Ling TH, Yang XL (2017) Rock mass collapse mechanism of concealed karst 
cave beneath deep tunnel. Int J Rock Mech Min 91: 133-138

Huang X, Li SC, Xu ZH, Guo M, Shi XS, Gao B, Zhang B, Liu L (2019) An attribute recognition model for safe thickness assessment between concealed karst cave and tunnel. J Cent South Univ 26: 955-969

Lee IN, Nam SW (2001) The study of seepage forces acting on the tunnel lining and tunnel face in shallow tunnels. Tunn Undergr Sp Tech 16: 31-40

Li SC, Yuan YC, Li LP, Ye ZH, Zhang QQ, Lei T (2015) Water inrush mechanism and minimum safe thickness of rock wall of karst tunnel face under blast excavation. Chinese Journal of Geotechnical Engineering 37(2): 313-320

Meng FS, Wang YC, Jiao QL, Wang YM, Li CY (2020) Analysis of the minimum safe thickness of water inrush in fault fracture zone based on the silo theory. Journal of Harbin Institute of Technology 52(2): 89-95

Qiao CS (2009) Study on tunnel construction technology in high-pressure water-rich filling large karst area (Sub-report 2). Research report, Beijing Jiaotong University, Beijing

Yang XL, Long ZX (2015) Roof collapse of shallow tunnels with limit analysis method. J Cent South Univ 22: 1926-1936

Yang ZH, Zhang JH (2016) Minimum safe thickness of rock plug in karst tunnel according to upper bound theorem. J Cent South Univ 23: 2346-2353

Yang ZH, Zhang R, Xu JS, Yang XL (2017) Energy analysis of rock plug thickness in karst tunnels based on non-associated flow rule and nonlinear failure criterion. J Cent South Univ 24: 29402950

Yang ZH, Yang XL, Xu JS, Li YX, Sun ZB (2017) Two methods for rock wall thickness calculation in karst tunnels based on upper bound theorem. Rock and Soil Mechanics 38(3): 801-809

Zhang Q, Bai SS, Gao Y, Du YL, Zhao WG, Liang GT (2018) Mechanics Model to Determine the Minimum Safe Thickness of Tunnel-face Rock Slab at a Fracture Zone. China J Highw Transp 31(10):141-149, 219 


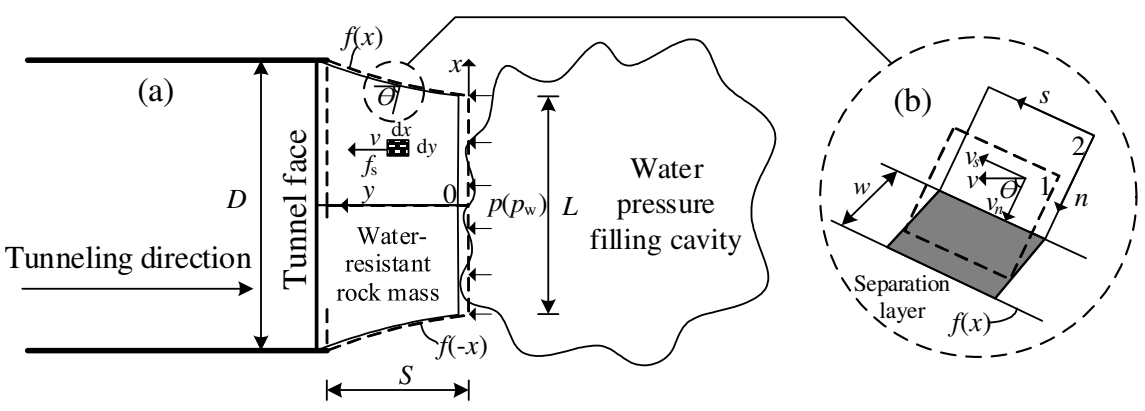

436

437

438

439

440

441

442

443

444

445

446

447

448

449

450

451

452

453

454

455

456

457

458

459

460

461

462

463

464

465

466

467

468

469

470

471

Fig. 1 Failure mode of the water-resistant rock mass

$\begin{array}{ll}\text { (a) Failure mode } & \text { (b) Deformation mode of the separation layer }\end{array}$ 
472

473

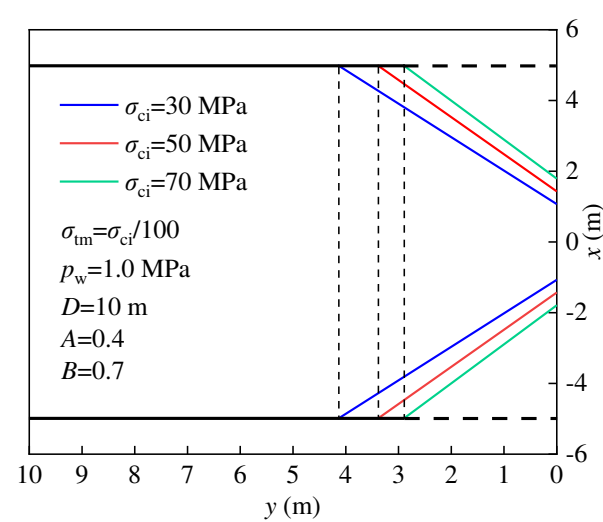

(a) Influence of the compressive strength

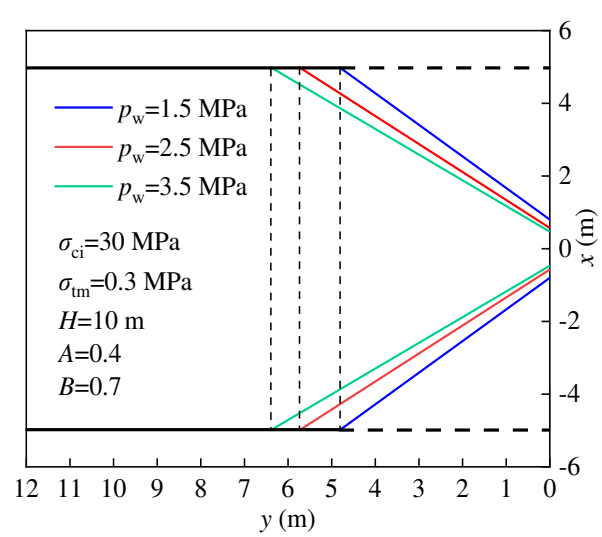

(c) Influence of the karst water pressure

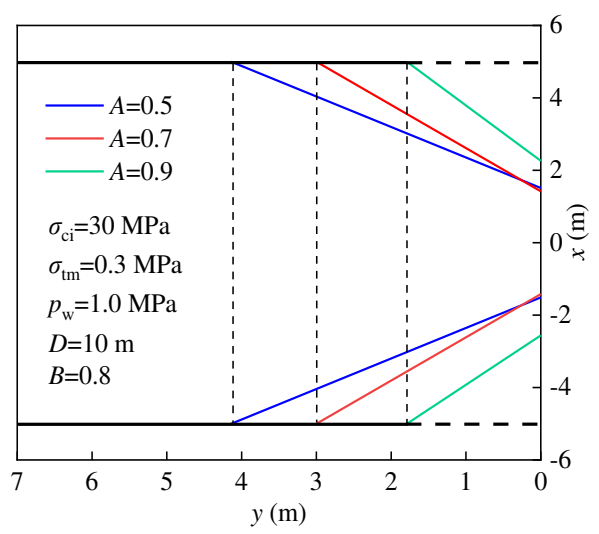

(e) Influence of the value of parameter $A$

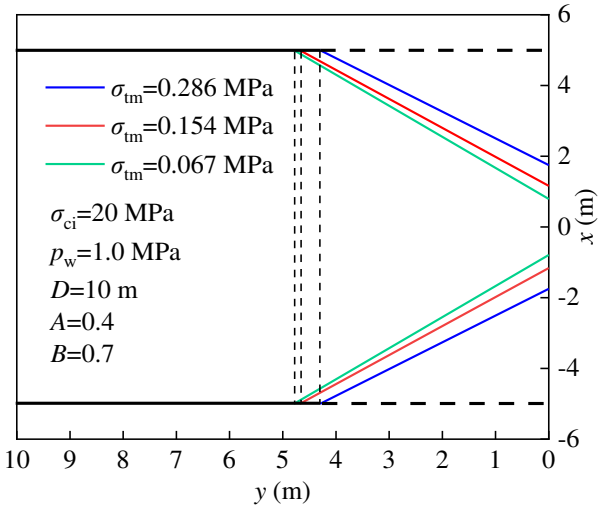

(b) Influence of the tensile strength

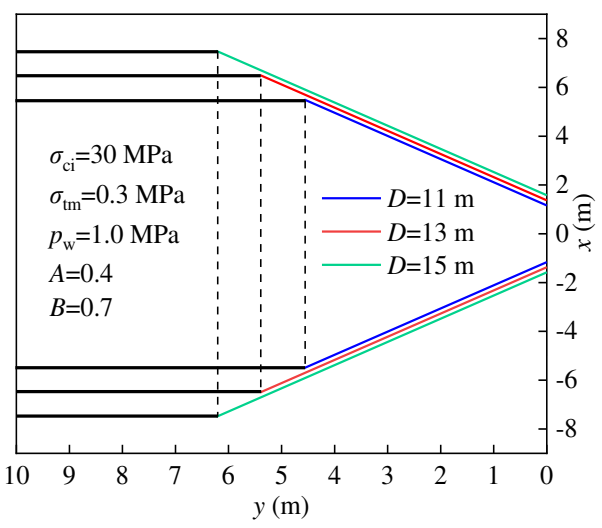

(d) Influence of the excavation section heights

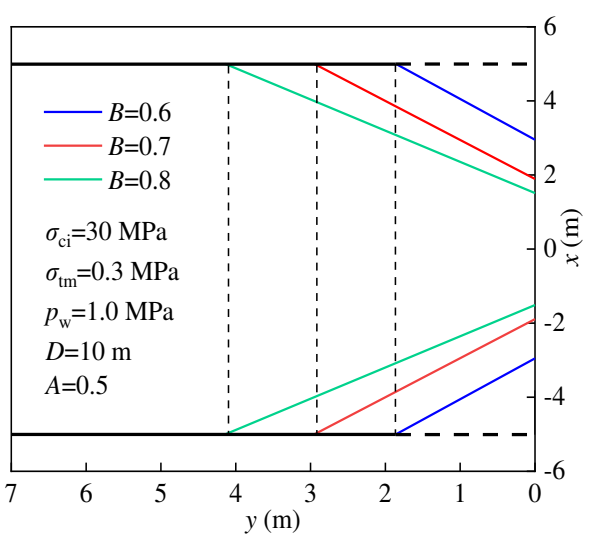

(f) Influence of the value of parameter $B$

Fig. 2 Influence of each factor on the failure shape and damage range of the water-resistant rock mass 


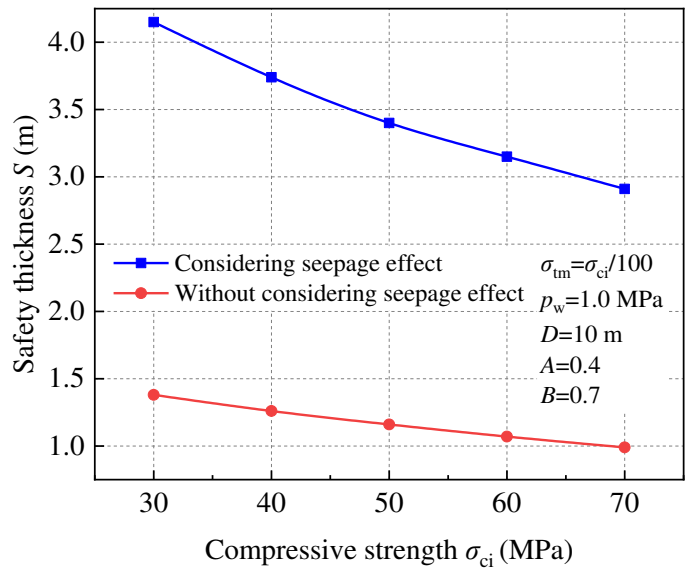

(a) Variation of safety thickness under the influence of compressive strength

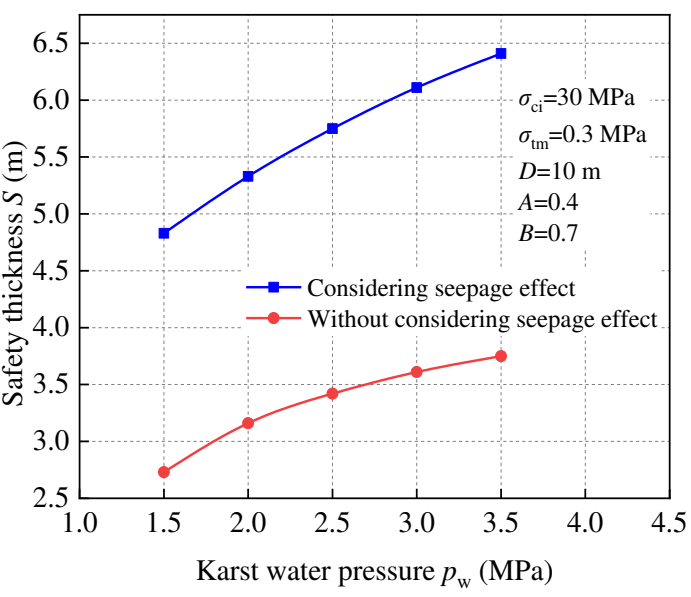

(c) Variation of safety thickness under the

493

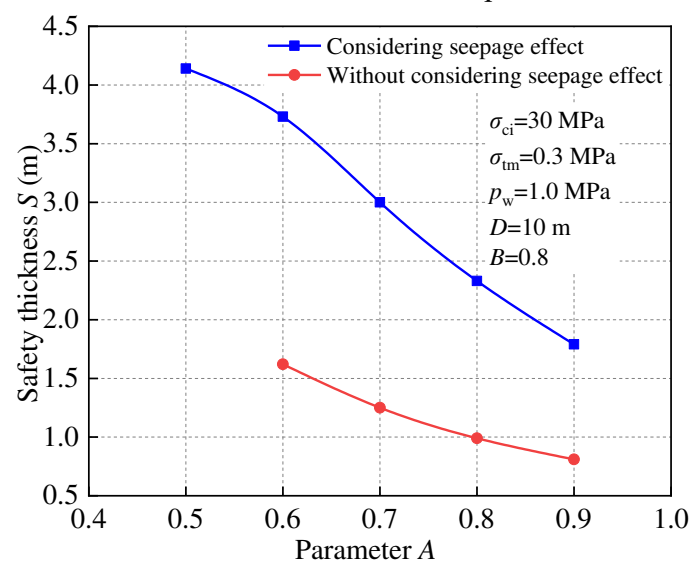

(e) Variation of safety thickness under the influence of parameter $A$

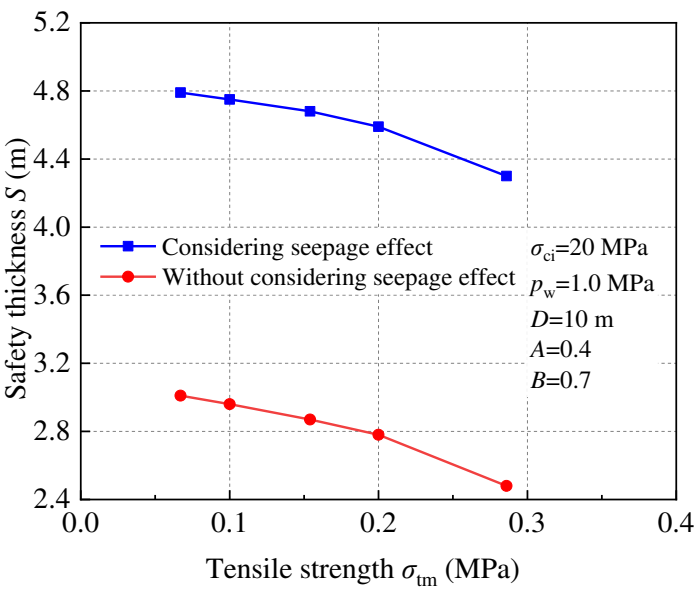

(b) Variation of safety thickness under the influence of tensile strength

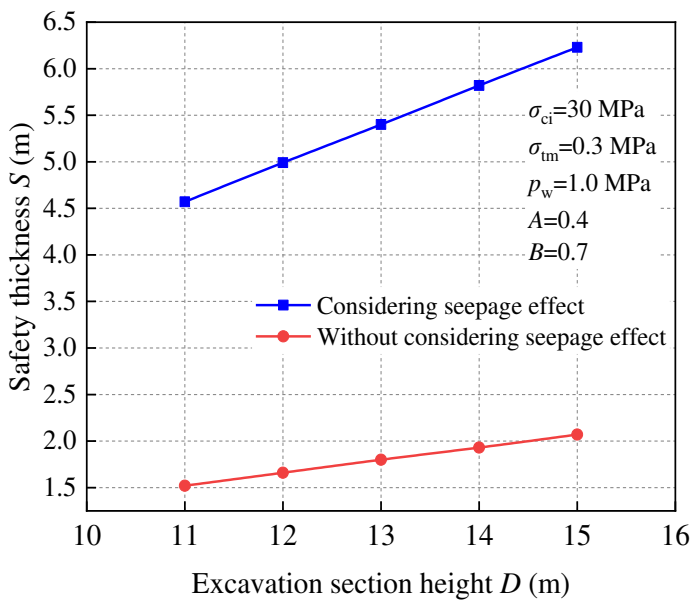

(d) Variation of safety thickness under the influence of excavation section height (f) Variation of safety thickness under the influence of parameter $B$

Fig. 3 Variation law of safety thickness under the influence of different factors 
Total length: $6640 \mathrm{~m}$

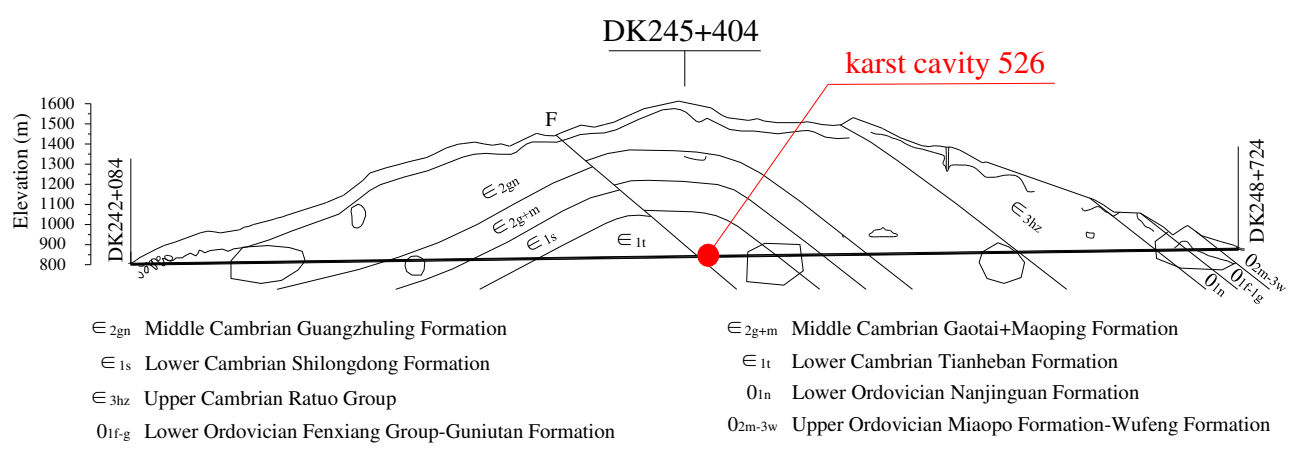

Fig. 4. Engineering geological profile of the Yunwushan tunnel and the karst cave 526 location 


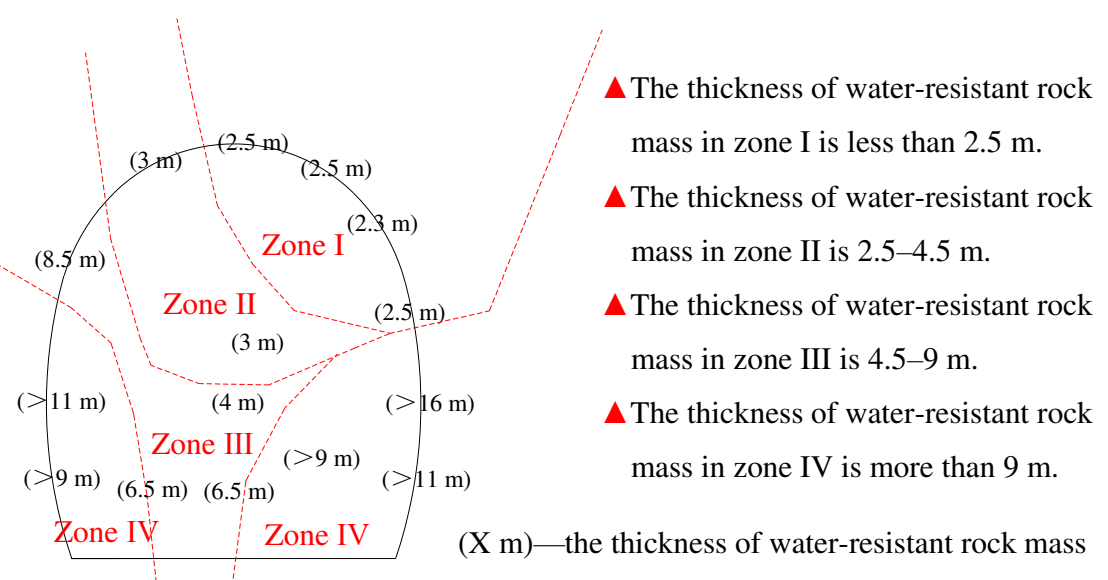

Fig. 5 Boundary locking value of karst cavity 526 in Yunwushan Tunnel 
Table 1 Critical safety thickness of the water-resistant rock mass with different surrounding rock grades

\begin{tabular}{ccccc}
\hline $\begin{array}{c}\text { Surrounding rock } \\
\text { grades }\end{array}$ & $\begin{array}{c}\text { Cohesion } c \\
(\mathrm{MPa})\end{array}$ & $\begin{array}{c}\text { Internal friction } \\
\text { angle } \varphi\left(^{\circ}\right)\end{array}$ & $\begin{array}{c}\text { Compressive strength } \\
\sigma_{\mathrm{ci}}(\mathrm{MPa})\end{array}$ & $\begin{array}{c}\text { Critical safety } \\
\text { thickness } S(\mathrm{~m})\end{array}$ \\
\hline I & $>2.1$ & $>60$ & $>15.67$ & $<1.03$ \\
II & $2.1-1.5$ & $60-50$ & $15.67-8.24$ & $1.03-1.68$ \\
III & $1.5-0.7$ & $50-39$ & $8.24-2.93$ & $1.68-3.13$ \\
IV & $0.7-0.2$ & $39-27$ & $2.93-0.65$ & $3.13-7.52$ \\
V & $<0.2$ & $<27$ & $<0.65$ & $>7.52$ \\
\hline
\end{tabular}

570

571

572

573

574

575 
Figures

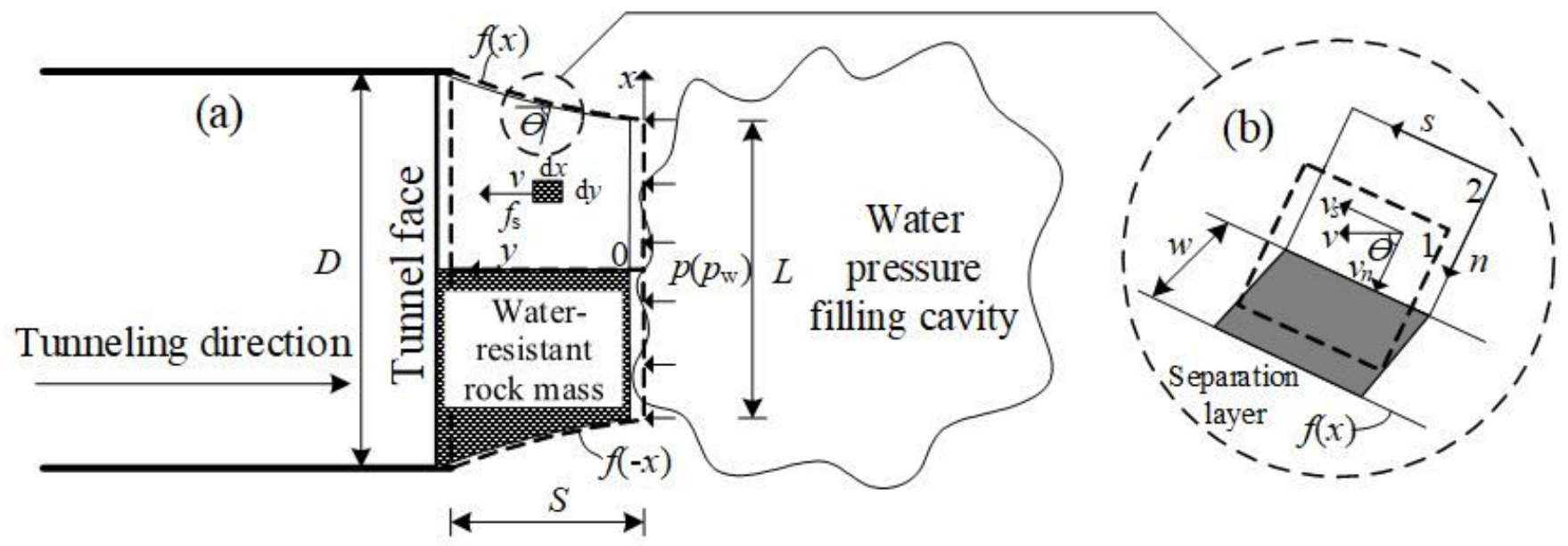

Figure 1

Failure mode of the water-resistant rock mass (a) Failure mode (b) Deformation mode of the separation layer 


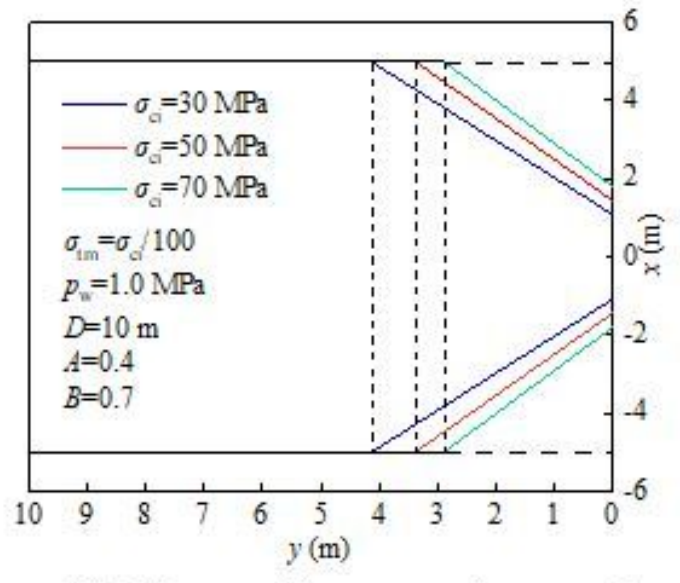

(a) Influence of the compressive strength

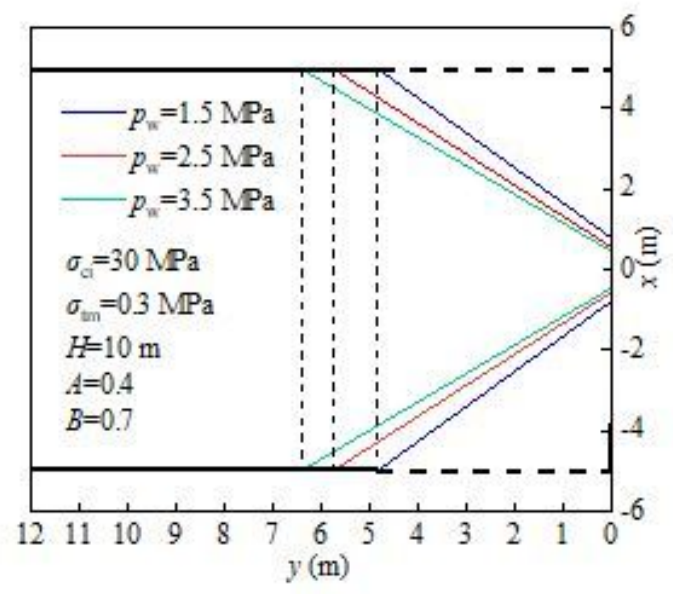

(c) Influence of the karst water pressure

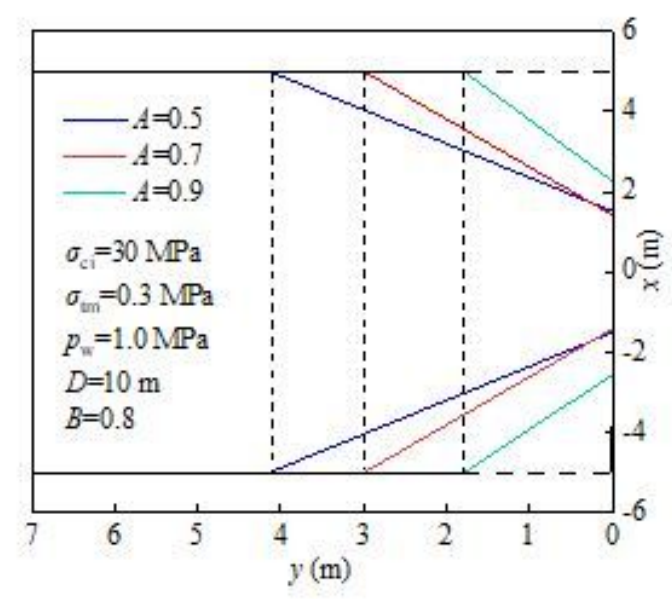

(e) Influence of the value of parameter $A$

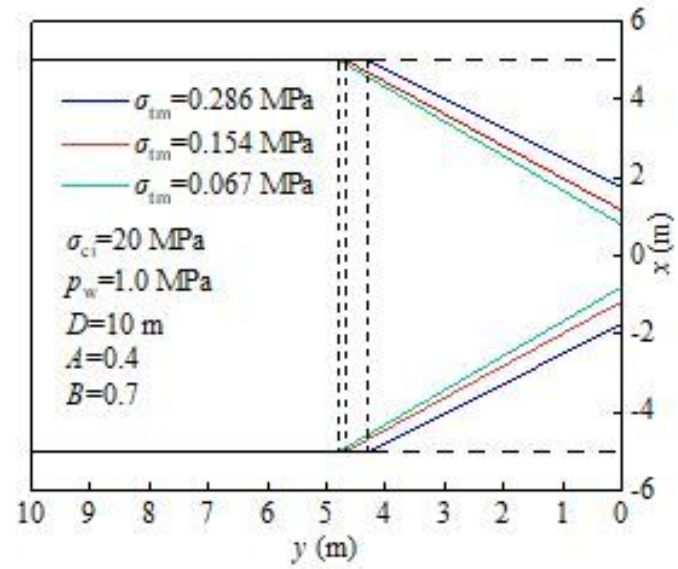

(b) Influence of the tensile strength

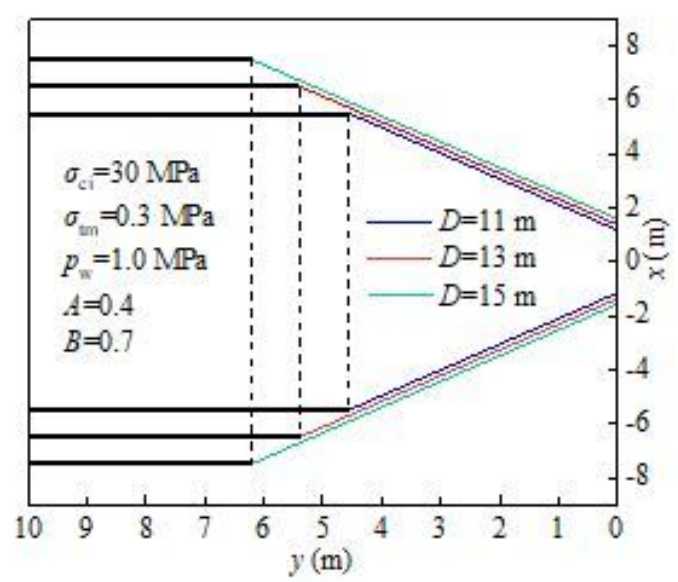

(d) Influence of the excavation section heights

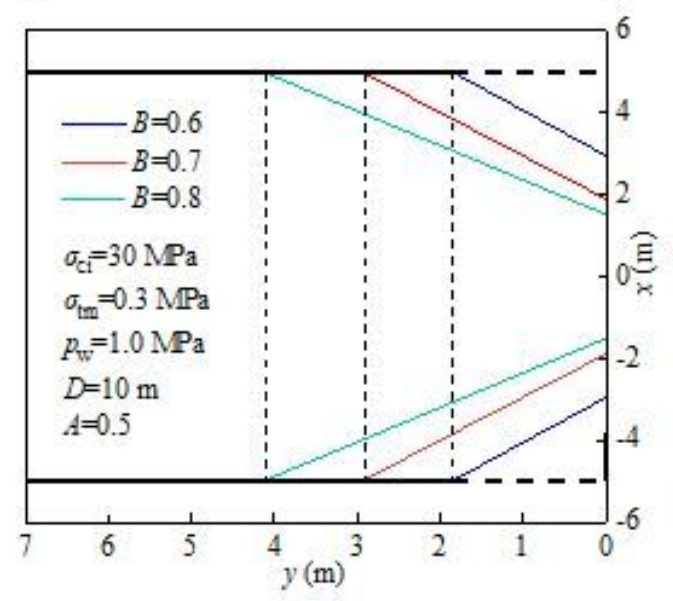

(f) Influence of the value of parameter $B$

\section{Figure 2}

Influence of each factor on the failure shape and damage range of the water-resistant rock mass 


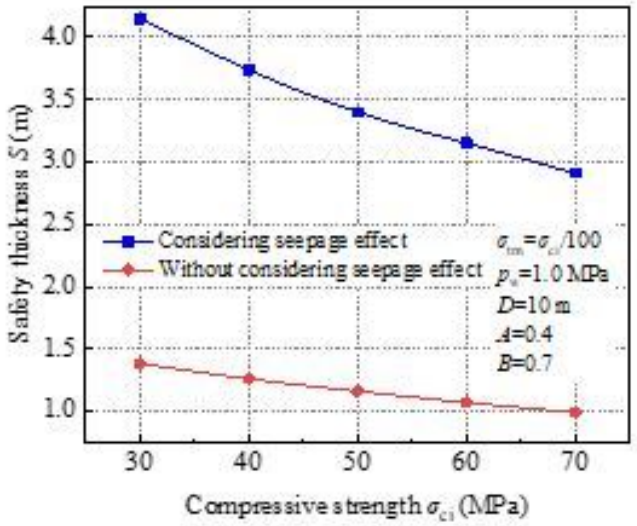

(a) Variation of safety thickness under the influence of compressive strength

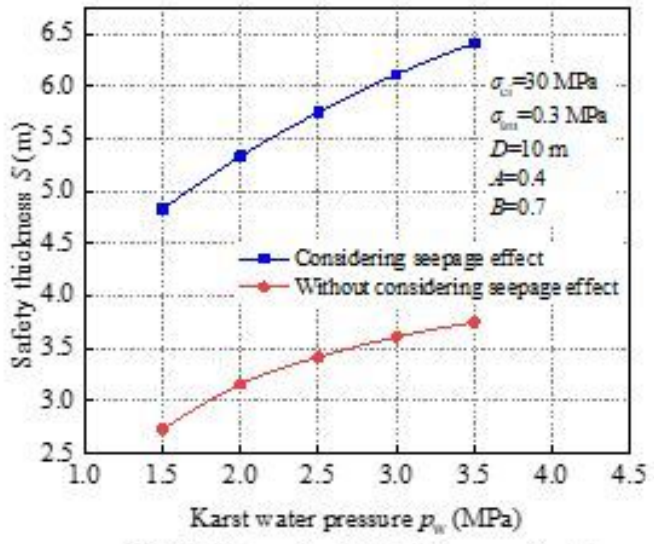

(c) Variation of safety thickness under the influence of karst water pressure

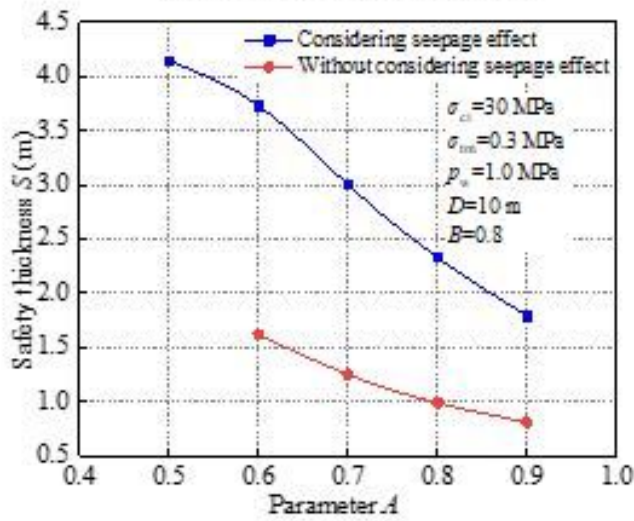

(e) Variation of safety thickness under the influence of parameter $A$

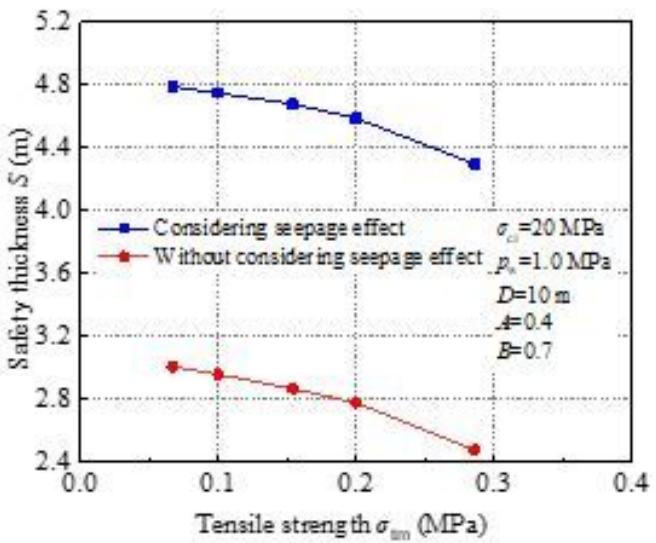

(b) Variation of safety thickness under the influence of tensile strength

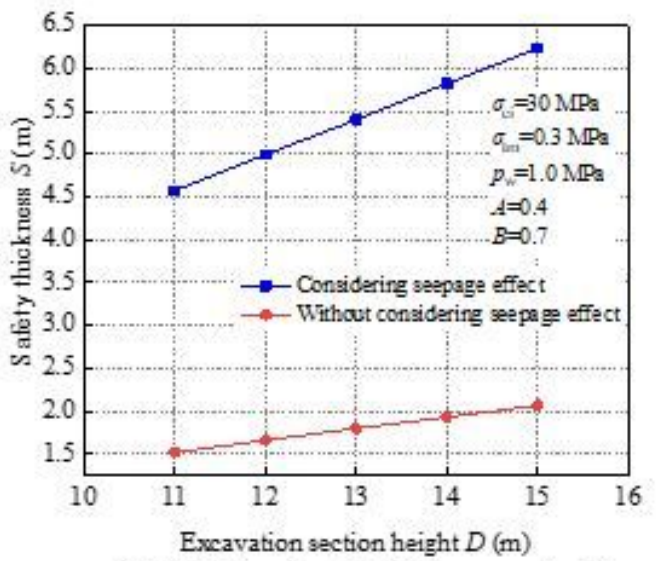

(d) Variation of safety thickness under the influence of excavation section height

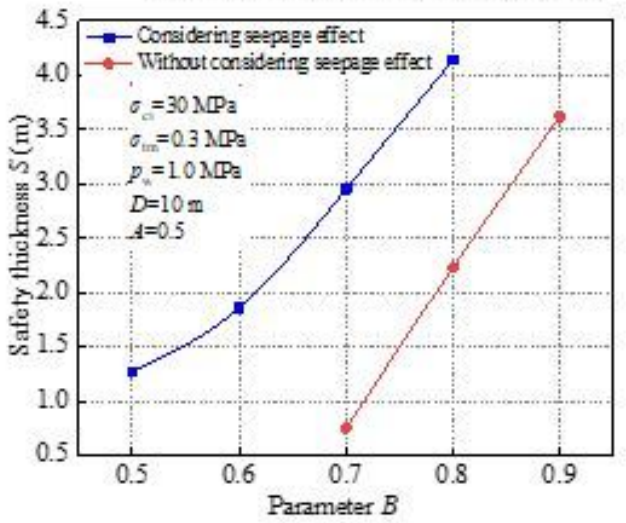

(f) Variation of safety thickness under the influence of parameter $B$

\section{Figure 3}

Variation law of safety thickness under the influence of different factors 
Total length: $6640 \mathrm{~m}$

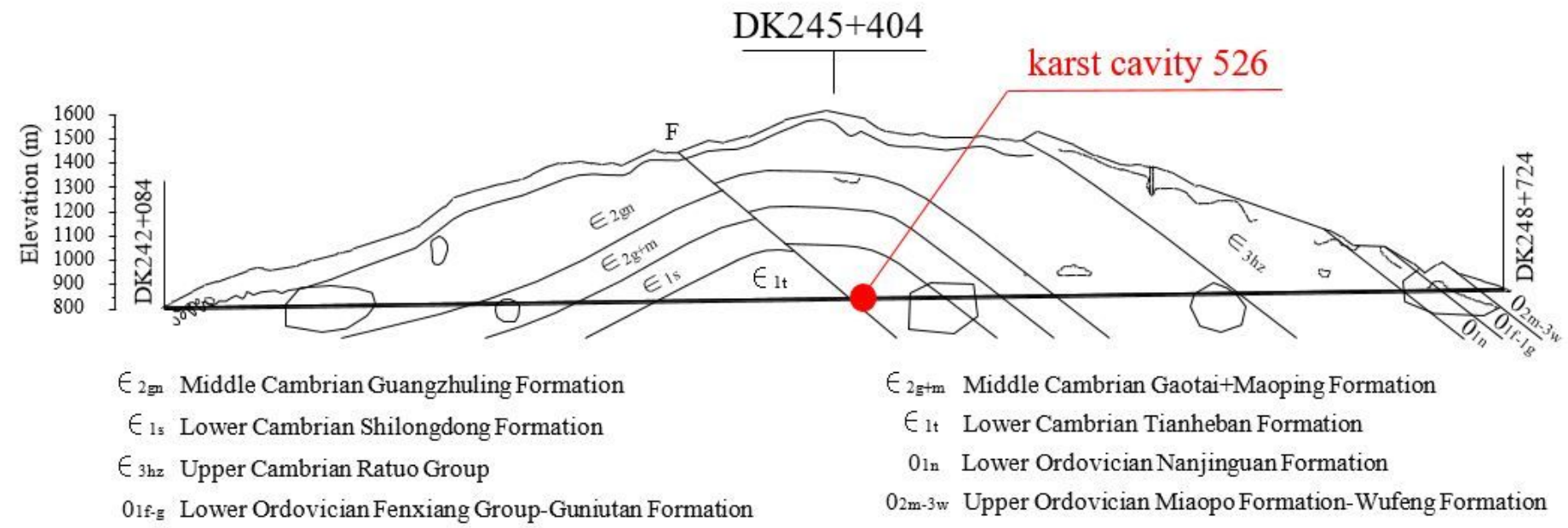

\section{Figure 4}

Engineering geological profile of the Yunwushan tunnel and the karst cave 526 location

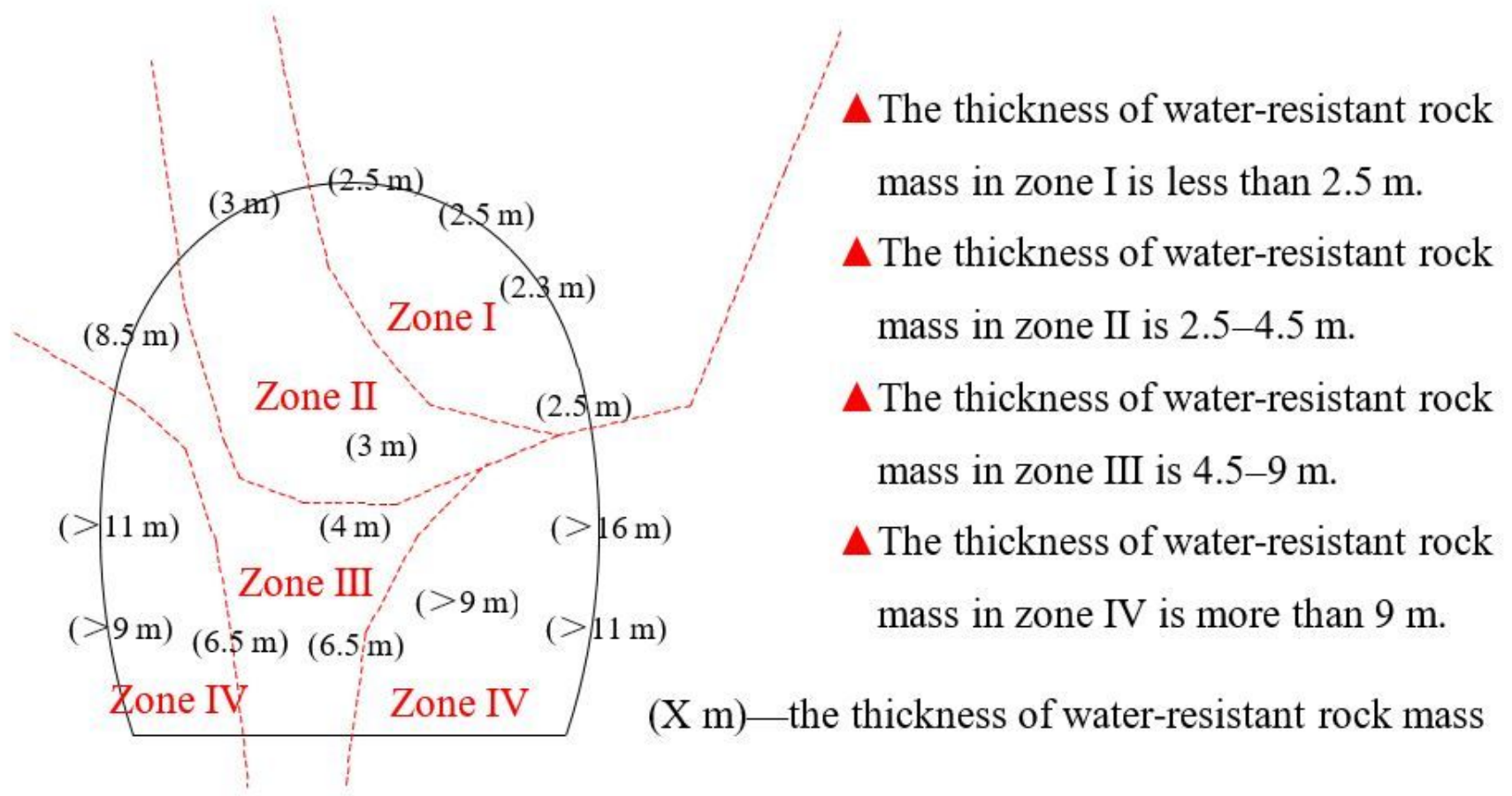

\section{Figure 5}

